\title{
Molecules and mechanisms controlling the active DNA demethylation of the mammalian zygotic genome
}

\author{
Jun-Yu Ma ${ }^{1}$, Teng Zhang ${ }^{1,2}$, Wei Shen ${ }^{1}$, Heide Schatten ${ }^{3}$, Qing Yuan Sun ${ }^{1,2 \bowtie}$ \\ ${ }^{1}$ College of Animal Science and Technology, Qingdao Agricultural University, Qingdao 266109, China \\ 2 State Key Laboratory of Reproductive Biology, Institute of Zoology, Chinese Academy of Sciences, Beijing 100101, China \\ ${ }^{3}$ Department of Veterinary Pathobiology, University of Missouri, Columbia, MO 65211, USA \\ $\triangle$ Correspondence: sunqy@ioz.ac.cn (Q. Y. Sun)
}

Received June 23, 2014 Accepted July 21, 2014

\begin{abstract}
The active DNA demethylation in early embryos is essential for subsequent development. Although the zygotic genome is globally demethylated, the DNA methylation of imprinted regions, part of repeat sequences and some gamete-specific regions are maintained. Recent evidence has shown that multiple proteins and biological pathways participate in the regulation of active DNA demethylation, such as TET proteins, DNA repair pathways and DNA methyltransferases. Here we review the recent understanding regarding proteins associated with active DNA demethylation and the regulatory networks controlling the active DNA demethylation in early embryos.
\end{abstract}

KEYWORDS active DNA demethylation, zygote, 5-hmC, 5-mC, preimplantation embryo, TET proteins

\section{INTRODUCTION}

Prior to fertilization, both the oocyte and spermatozoon have formed a gamete-specific DNA methylation pattern and specific genomic imprinting (Kobayashi et al., 2012; Smith et al., 2012). For the spermatozoon, $80 \%-90 \%$ of low density CpG sites are methylated whereas only $50 \%$ are methylated in the oocyte (Kobayashi et al., 2012). For the moderate or high density $\mathrm{CpG}$ sites, both oocyte and sperm genomes are hypomethylated. At the transposable element DNA regions, the sperm genome is highly methylated but the oocyte genome is only moderately methylated (Kobayashi et al., 2012). Reduced representation bisulfite sequencing result showed that the number of oocyte-specific methylated DNA regions was 376 and that of the spermatozoon was 4894 (Smith et al., 2012). In addition to the imprinting control regions (ICRs) and gamete-specific methylated CpG sites, whole-genome shotgun bisulfite sequencing data of the oocyte and spermatozoon also showed that more than 1600 $\mathrm{CpG}$ islands (CGIs) were differentially methylated between oocytes and spermatozoa (Kobayashi et al., 2012).

After a spermatozoon fertilizes the oocyte, the protamines on the sperm chromatin are replaced by histones (van Meel and Pearson, 1979) before paternal pronucleus (PPN) and maternal pronucleus (MPN) formation. During subsequent early embryo development, the zygotic genome is firstly demethylated from the zygote to morula stage and the genomic DNA is then de novo methylated at the blastocyst stage (Ma et al., 2012; Santos et al., 2002; Smith et al., 2012) (Fig. 1). During demethylation of the zygotic genome, different demethylation mechanisms are utilized in maternal or paternal genomes. The paternal genome is actively demethylated (DNA replication independent and mediated by enzymes) whereas the maternal genome is mainly passively demethylated (diluted through DNA replication) (Inoue and Zhang, 2011; Rougier et al., 1998). For the active DNA demethylation, 5-methylcytosines (5-mCs) can be oxidized by the tet methylcytosine dioxygenase 3 (TET3) into 5-hydroxymethylcytosines (5-hmCs) (lqbal et al., 2011; Ruzov et al., 2011). Although the maternal and paternal genomic CGls undergo global DNA demethylation, by comparing the DNA methylation profiles of gametes with those of the blastocyst or inner cell mass (ICM) cells, evidence has shown that about half of the gamete-specific DNA methylation patterns is partially maintained during preimplantation embryo development (Borgel et al., 2010; Kobayashi et al., 2012; Smallwood et al., 2011). 
A

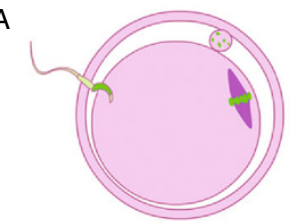

$A^{\prime}$

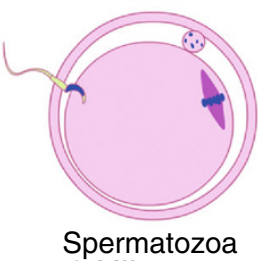

\& MII oocyte

B

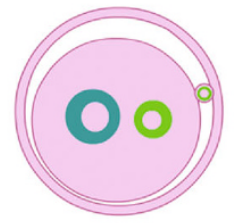

$B^{\prime}$

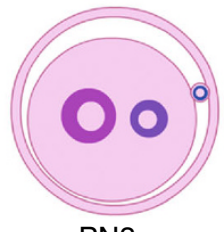

PN3

C

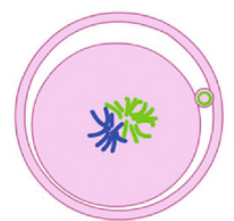

$C^{\prime}$

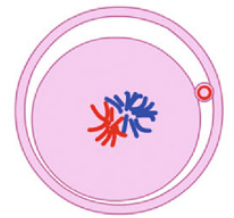

Metaphase zygote

D

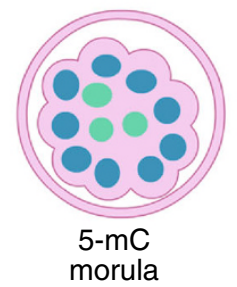

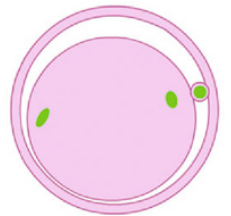
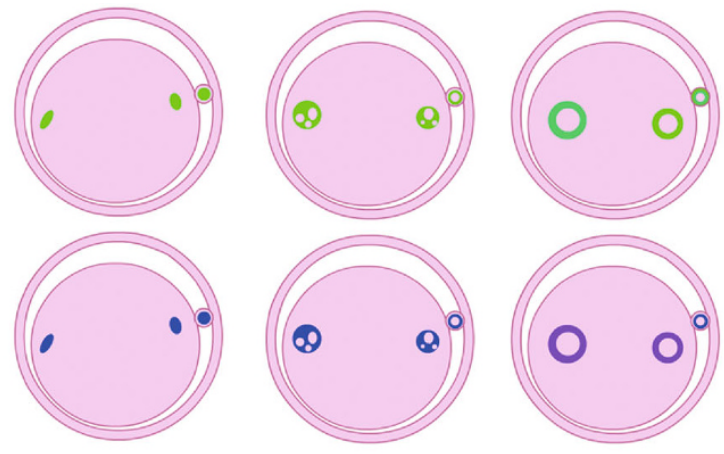

PNO

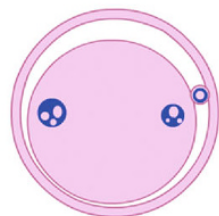

PN1
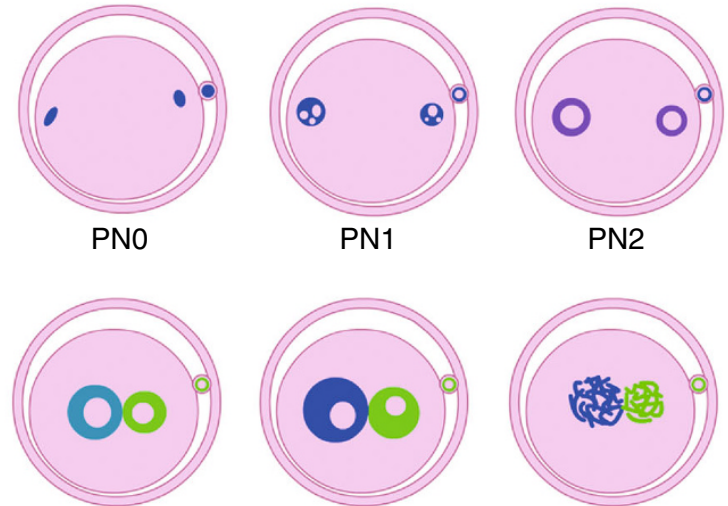

PN2
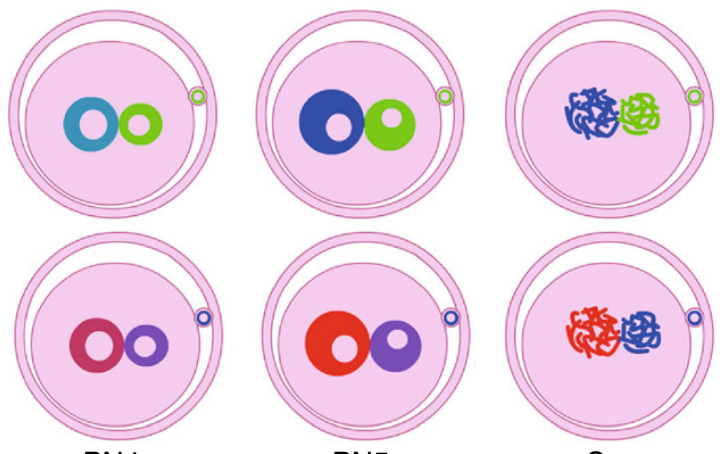

PN5
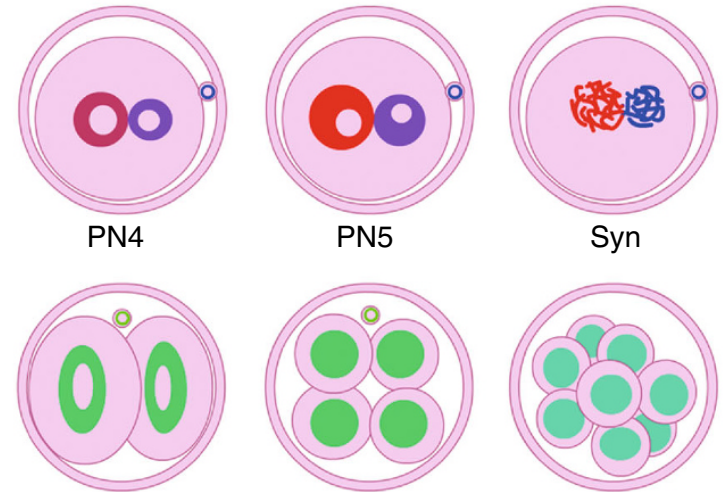

Syn
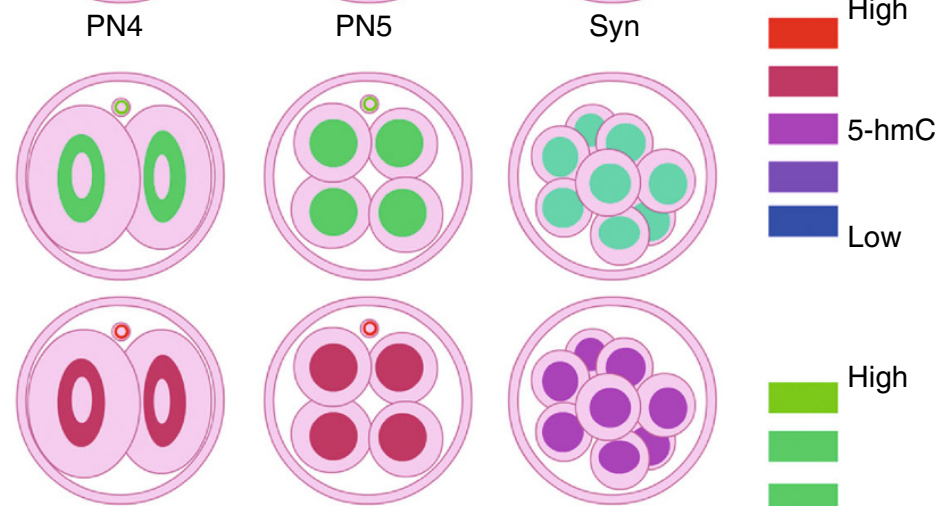

2-Cells

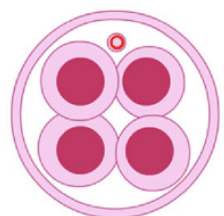

4-Cells
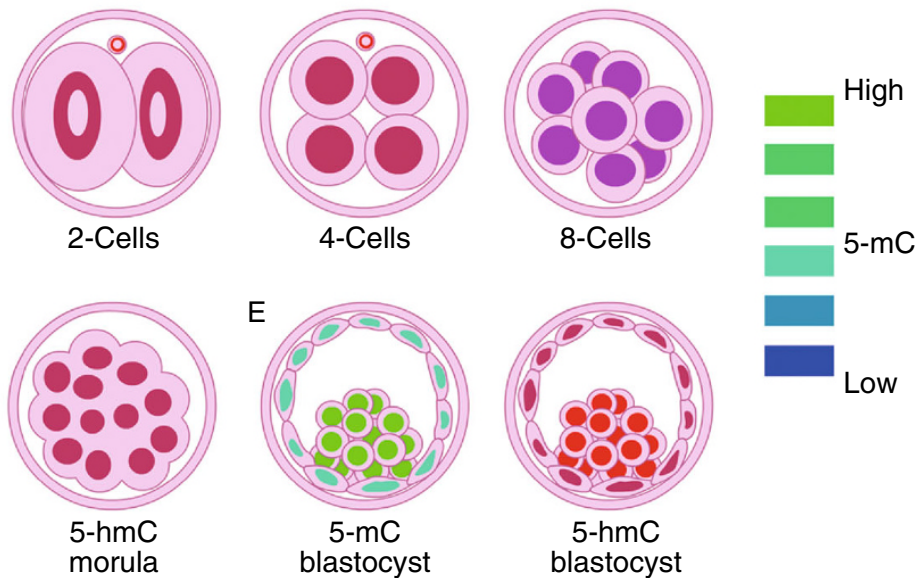

Figure 1. DNA methylation dynamics in mouse preimplantation embryos. (A, B, C, D left and $E$ left), dynamics of 5-mCs in oocyte and preimplantation embryos; $\left(A^{\prime}, B^{\prime}, C^{\prime}, D\right.$ right and $E$ right), dynamics of 5-hmCs in oocyte and preimplantation embryos.

Recent studies have revealed more details about the mechanisms underlying active DNA demethylation and the essential roles of zygotic genome reprogramming. Here we mainly review details of zygotic genome DNA demethylation and the molecules controlling active DNA demethylation during mammalian early embryo development.

\section{TET PROTEINS MEDIATE ACTIVE DNA DEMETHYLATION}

There are three TET proteins exist in mouse, Tet1, Tet2 and Tet3. All the TET proteins contain a cysteine-rich region and a double-stranded $\beta$-helix fold at their C-terminals taking 
functions as the catalytic domain. The Tet1 and Tet3 also contain a CXXC region, which can bind to the genomic CpG islands (Tan and Shi, 2012; Zhao and Chen, 2013). It was firstly discovered in Purkinje neurons and the brain that TET proteins mediate active DNA demethylation (Kriaucionis and Heintz, 2009; Tahiliani et al., 2009). TET proteins were shown to be partners of myeloid/lymphoid leukemia protein (MLL) protein, and oxidized 5-mC to 5-hmC depending on 2-oxoglutarate and $\mathrm{Fe}(\mathrm{II})$ and Vitamin $\mathrm{C}$ (Blaschke et al., 2013; Tahiliani et al., 2009). Further studies showed that the 5 -hmCs could be further transformed into 5 -formylcytosines (5-fCs) and 5-carboxylcytosines (5-caCs) by the TET proteins, and that the 5-fCs and 5-caCs could be replaced by cytosines through the base excision repair (BER) pathway (He et al., 2011; Ito et al., 2011; Song et al., 2013). The 5-hmC concentration in mammalian genomic nucleotide bases was less than 1\% (Kriaucionis and Heintz, 2009), and traditional bisulfite sequencing methods could not distinguish 5-hmCs from 5-mCs (Huang et al., 2010), which increased the difficulty of investigating the biological functions of 5-hmCs. By using the biotin modified 5-hmC DNA fragments enrichment sequencing and immunofluorescence labeling, it was shown that the 5-hmCs were widely distributed in tissues and cultured cells (Ruzov et al., 2011; Song et al., 2011). The 5-hmC genome localization data of mouse embryonic stem cells (ESCs) showed that the 5-hmCs were mainly enriched at the gene body regions and formed peaks in the vicinity of transcription start sites (TSSs) (Williams et al., 2011). Data showed that $58 \%$ of 5 -hmCs were identified at the gene body regions, and $6 \%$ at the promoter regions (Wu et al., 2011). Referring to the genome-wide ChIP-Seq data of chromatin code proteins, most 5 -hmCs highly enriched promoters showed intensive histone $\mathrm{H} 3$ trimethyl Lys4 (H3K4me3) or H3K4me3/histone H3 trimethyl Lys27 (H3K27me3) signals, which indicated the 5-hmC highly enriched promoters were mostly corresponding to the active or the poised genes (Ficz et al., 2011; Pastor et al., 2011).

\section{ACTIVE DNA DEMETHYLATION IN EARLY EMBRYOS}

Active DNA demethylation in preimplantation embryos was firstly discovered in the mouse zygotic PPN (Mayer et al., 2000; Oswald et al., 2000). Immunofluorescence labeling results showed that the signals of PPN 5-mCs decreased firstly at the PN2 stage, and reached the lowest level at the PN4-PN5 stage. By subsequent dilution of the 5-mCs of paternal and maternal genomes by DNA replication-dependent passive DNA demethylation, the total genomic DNA 5 -mCs reached the lowest level at the morula stage. At the blastocyst stage, the genomic DNA was remethylated (Santos et al., 2002).

The 5-hmC was firstly detected by immunofluorescence staining at both paternal and maternal pronuclei in the PN1 zygote. With zygote development, the 5-hmCs increased mainly in the PPN, which coincided with the decrease of PPN 5-mCs (Iqbal et al., 2011; Wang et al., 2014). Immunofluorescence labeling data showed that the $5-\mathrm{hmC}$ also existed in the blastomeres of all embryo stages (Ruzov et al., 2011) (Fig. 1). Using chromosome spreading and 5-hmC labeling of blastomeres from the zygote to 8-cell embryo, Inoue and Zhang observed that 5-hmCs mainly localized at the paternal chromosomes and most 5-hmC positive genomic regions were demethylated in a DNA replicationdependent manner (Inoue and Zhang, 2011). However, very recent evidence showed that the 5 -hmCs, the 5 -fCs and the 5 -caCs in early embryos were not just demethylated passively but that most of the oxidized derivatives of 5-mCs were demethylated actively (Wang et al., 2014).

\section{ACTIVE DNA DEMETHYLATION-ASSOCIATED MOLECULES IN EARLY EMBRYOS}

The DNA methylation modification proteins could be classified into three categories: the DNA methyltransferase enzymes like DNA de novo methylation enzymes Dnmt3a, Dnmt3b and Dnmt3l, and the DNA methylation maintaining enzyme Dnmt1; the proteins that function in the active DNA demethylation pathways, and the unclassified factors such as the metabolite folic acid (Pufulete et al., 2005) and environment chemical biphenol A (Singh and Li, 2012). These molecules regulate the genomic DNA demethylation by coordination or by taking actions alone. However, the mechanisms by which they target the genomic-specific regions, regulate specific gene expression and participate in different developmental events are still unresolved. Here we summarize the functions of these proteins in preimplantation embryos. The expression levels and cellular localization of the main DNA demethylation associated proteins are displayed in Fig. 2.

\section{Roles of TET proteins in zygotic genome reprogramming}

During early embryo development, all three TET proteins are expressed. QRT-PCR results showed that Tet1 was highly expressed at the morula stage, Tet2 mRNAs existed from the zygote stage through the blastocyst stage, and Tet3 mRNAs mainly existed at the zygote stage. In mouse embryonic stem cells (ESCs), both Tet1 and Tet2 could bind to the Nanog gene promoter to catalyze 5-mC oxidation (Costa et al., 2013). Meanwhile, Gao et al. proved that Tet1 could be used to replace the Oct4 of Yamanaka factors (Oct4, Sox2, KIf4 and cMyc, OSKM) to induce pluripotency in somatic cells (Gao et al., 2013). Recent data also showed that the OySyNyK [highly efficient modified factors of Oct4, Sox2 and Nanog, which could induce the expression of Oct4-GFP of mouse embryonic fibroblast (MEF) as early as $24 \mathrm{~h}$ ] increased Tet 1 expression at an early stage of somatic cell reprogramming (Zhu et al., 2014). A previous study 

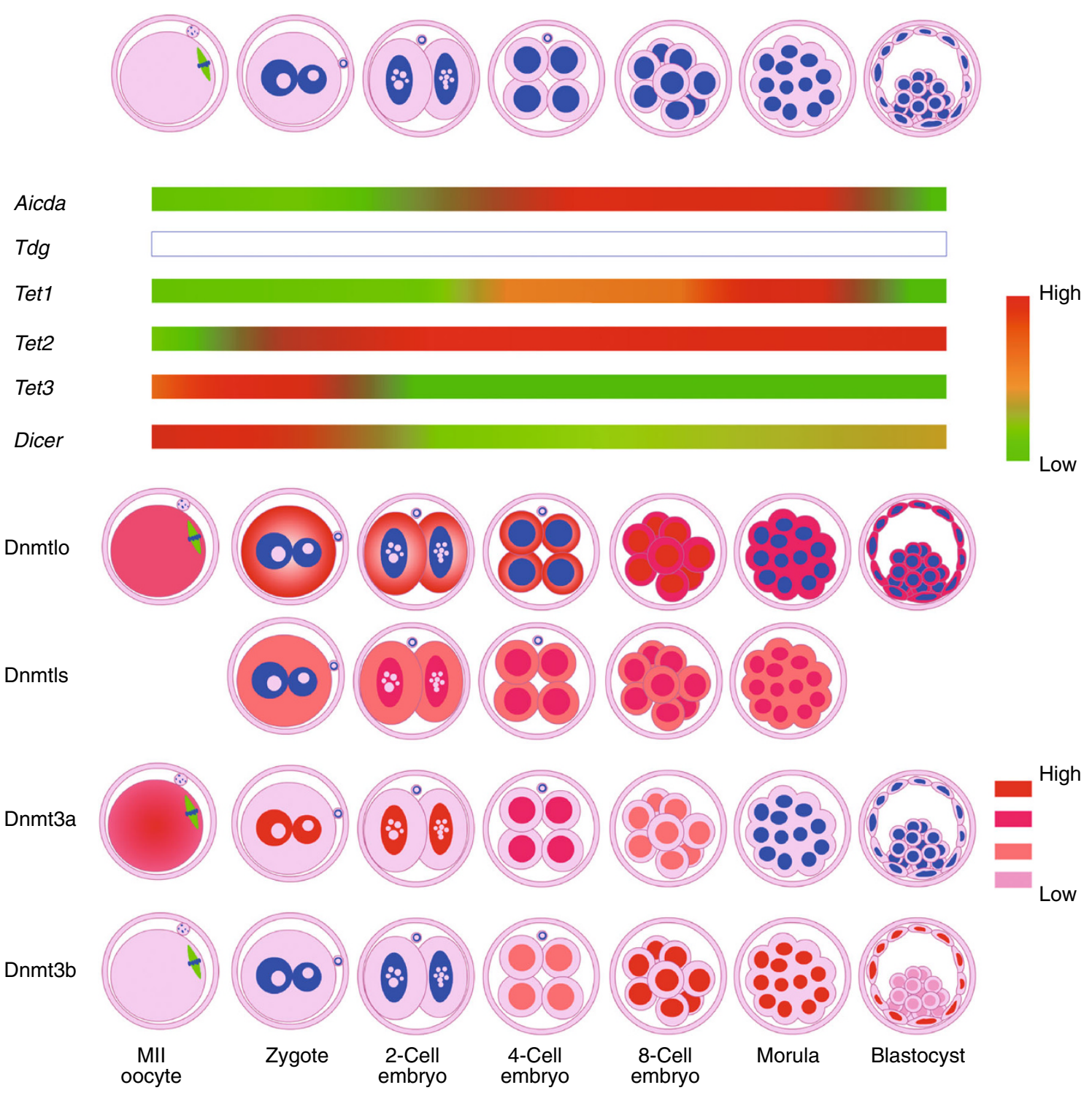

Figure 2. Expression patterns of DNA demethylation-associated genes in mouse preimplantation embryos. Aicda, (Kang et al., 2014); Tet1, Tet2 and Tet3, (Yu et al., 2013); Dicer1, (Murchison et al., 2007); Dnmt1o and Dnmt1 s, (Cirio et al., 2008; Hirasawa et al., 2008; Howell et al., 2001; Kurihara et al., 2008); Dnmt3a and Dnmt3b, (Hirasawa et al., 2008). Gene symbol: italic, mRNAs; bold regular, protein localization.

showed that the expression of Tet2 but not Tet1 or Tet3 was induced at the early stage of MEF reprogramming using OSKM and that the Tet2 protein could target the genomic sites of Nanog and Esrrb (Doege et al., 2012). For the human, evidence showed that TET2 but not TET1 or TET3 was essential for somatic cell reprogramming (Wang et al., 2013). By depletion of Tet1 and Tet2 in ESCs, it was shown that Tet1 and Tet2 indeed played distinct roles in DNA demethylation. Tet 1 mainly targeted the transcription start sites whereas Tet2 mainly targeted the gene bodies (Huang et al., 2014). All the results from ESCs and iPSCs indicate that both Tet1 and Tet2 are associated with maintaining pluripotency of early embryonic cells.

Tet3 was mainly expressed in the zygote and located at the PPN (Nakamura et al., 2012). After knocking down Tet3 expression in mouse zygotes using siRNAs, the demethylation of PPN was diminished (Wossidlo et al., 2011), but the transcription activity showed no significant difference between Tet3 knock-down zygotes and normal zygotes (Inoue et al., 2012). In addition, transcript levels of transposable elements like LINE1, ERVL as well as the major satellite showed no obvious changes in zygotes or 2-cell 
embryos after Tet3 knock-down (Inoue et al., 2012), indicating that the global transcription of the zygote might not be affected by PPN active demethylation. In the Tet3-deficient zygotes, the activation of paternal Oct4 gene was delayed, the reprogramming ability of zygotes was decreased, and the developmental failure of offspring increased ( $\mathrm{Gu}$ et al., 2011), indicating that the epigenetic reprogramming induced by Tet3 at the zygote stage was important for further embryo development.

The Dppa3 (developmental pluripotency associated 3, also named PGC7 or Stella), is essential for the transition from the Non-Surrounded Nucleolus (NSN) type oocytes to the Surrounded Nucleolus (SN) type oocytes (Liu et al., 2012; Ma et al., 2013). When Dppa3 was depleted in the oocytes, the fertilized embryos could not develop beyond the 4-cell embryo stage (Bortvin et al., 2004). Evidence showed that the Dppa3 was mainly recruited to the MPN in zygote by the histone $\mathrm{H} 3 \mathrm{~K} 9 \mathrm{me} 2$ to prevent the demethylation of MPN 5 -mCs, when the zygotes were microinjected with the mRNAs of lysine (K)-specific demethylase 3A (Kdm3a, also known as Jhdm2a) which specially demethylates the H3K9me1 and H3K9me2, the levels of MPN H3K9me2 and Dppa3 decreased and the $5-\mathrm{hmCs}$ level in MPN were increased (Nakamura et al., 2012). When Dppa3 was depleted, the 5-mCs of MPN could be oxidized to 5-hmCs by the TET proteins (Wossidlo et al., 2011). It was also shown that the DNA methylation levels of maternal imprinted genes like Peg1, Peg3 and Peg10, paternal imprinted genes like $H 19$ and Rasgrf1 and the transposable element IAP could not be maintained in the Dppa3-depleted zygote, whereas the DNA methylation levels of maternal imprinted genes Snrpn and Peg5, paternal imprinted genes Meg3 and LINE1 showed no obvious change when Dppa3 was depleted (Nakamura et al., 2007).

In addition to Dppa3, Tet3 protein localization is also controlled by the O-linked $\beta$-GIcNAc (O-GIcNAc) transferase (Ogt) and activation-induced cytidine deaminase (Aicda, also known as Aid). Tet3, but not Tet1 or Tet2, would be transferred to the cytoplasm when O-GlcNAcylated by Ogt (Zhang et al., 2014). When co-expressed with Aicda, the nuclear TET proteins would be translocated to the cytoplasm (Arioka et al., 2012).

\section{DNA methyltransferases}

In preimplantation embryos, there are two isoforms of Dnmt1. The oocyte-specific Dnmt1o is mainly located at the cytoplasm of preimplantation embryonic blastomeres and enters the nucleus only at the 8-cell embryo stage (Howell et al., 2001). The oocyte-inherited somatic form Dnmt1s mainly existed at the zygote and 2-cell embryo stage, and at the 2-cell embryo stage the zygotic-originated Dnmt1s were expressed (Cirio et al., 2008). Dnmt1s located to the cytoplasm at the zygote stage and entered the nucleus in subsequent preimplantation embryo stages (Cirio et al., 2008) (Fig. 2). It was shown that maternal Dnmt1 was essential for the maintenance of genomic imprinting and the DNA methylation levels of transposable element IAP (Gaudet et al., 2004; Howell et al., 2001), H19, Snrpn and Peg3 (Howell et al., 2001).

Both Dnmt3a and Dnmt3b are responsible for DNA de novo methylation, however, the target regions of Dnmt3a and Dnmt3b are not fully overlapping. The methylation of pericentric satellite DNA is controlled by Dnmt3b (Okano et al., 1999). The DNA methylation of genomic CGIs are mainly controlled by Dnmt3a with its parter Dnmt3I (Smallwood et al., 2011). The establishment of DNA methylation and its maintenance are regulated by the histone modifications (Kelsey and Feil, 2013). For example, the chromatin binding pattern of Dnmt3a showed negative correlation with that of the H3K4me3 (Smallwood et al., 2011). In addition to DNA de novo methylation activity, new evidence also showed that Dnmt3a and Dnmt3b could transform the 5-hmC to cytosines without the BER pathway (Chen et al., 2012), indicating the possible dual functions of Dnmt3a and Dnmt3b in preimplantation embryos.

\section{DNA damage repair associated proteins}

During preimplantation embryo development, DNA doublestrand breaks (DSB) occurred spontaneously at the zygotic PPN and blastomeres of 4-cell embryo, 8-cell embryo, morula and blastocyst (Ziegler-Birling et al., 2009). At the zygote stage, DNA DSBs coincided with the DNA replication of PPN and MPN. The DNA DSB marker, $\mathrm{yH} 2 \mathrm{~A} . \mathrm{X}$ foci, appeared earlier and more abundant in PPN than in MPN (Derijck et al., 2008; Wossidlo et al., 2010). Although there was still no evidence proving the correlation between DNA DSBs and active DNA demethylation, chromosome spread results showed that the DNA DSB-induced sister chromatid exchange occurred in early embryos which might dilute the 5-mC on a single chromatid (Inoue and Zhang, 2011).

In addition to $\mathrm{YH} 2 \mathrm{~A} . \mathrm{X}$-marked DNA DSBs, proteins associated with BER and DNA single strand breaks (SSBs), such as the Parp1 [poly (ADP-ribose) polymerase family, member 1] and Xrcc1 (X-ray repair complementing defective repair in Chinese hamster cells 1 ), were also recruited to the paternal nucleus DNA (Hajkova et al., 2010). When the BER pathway was inhibited by apurinic/apyrimidinic endonuclease 1 (APE1) inhibitor (CRT0044876) or poly (ADP-ribose) polymerase family protein (PARP) inhibitor (3-aminobenzamide or ABT-888), the DNA demethylation of zygotic PPN became reduced (Hajkova et al., 2010).

In the BER pathway, the cytidine deaminase Aicda and thymine DNA glycosylase ( $\mathrm{Tdg}$ ) can recognize and excise the damaged bases. The Tdg could excise the 5-caC produced by TET proteins and the 5 -hmUs which could be produced by deamination of $5-\mathrm{hmC}$ mediated by Aicda (Ma et al., 2012). Tdg and Aicda play important roles in regulating DNA demethylation, however, both the Tdg and Aicda proteins are not detected in the mouse zygote (Hajkova et al., 2010). Tdg null embryos died at about embryonic day 
10.5-12.5. Data from Tdg null MEFs showed that the DNA methylation levels increased in $\mathrm{CpG}$ islands. In addition, the histone modification H3K4me2 decreased whereas H3K27me3 and H3K9me3 increased in Tdg null MEFs (Cortazar et al., 2011).

The damage-specific DNA binding protein $1(\mathrm{Ddb} 1)$ is the subunit of UV-DNA damaged DNA-binding protein complex and also the component of CUL4 complex which ubiquitinates the histones at UV-DNA damaged sites (Chen et al., 2001; Lan et al., 2012). When Ddb1 was depleted in the zygote, the Tet3-mediated 5-mC hydroxylation was blocked and the 5-mC level at PPN was maintained (Yu et al., 2013). All the above results indicate that the DNA repair pathway not only exerts functions directly on the active DNA demethylation but also maintains the progression of active DNA demethylation and repairs the active DNA demethylation-induced DNA damages.

\section{Other DNA demethylation-associated proteins or molecules}

Dicer1 is a critical enzyme controlling the synthesis of miRNAs. In the Dicer1 null cells, the decrease of miR-290 cluster miRNAs increased the expression of retinoblastomalike 2 protein $(\mathrm{Rbl} 2)$ which suppressed the expression of DNMTs (Benetti et al., 2008). RT-PCR data showed that the Dicer1 mRNAs mainly existed in fully grown oocytes and sharply decreased at the 2-cell embryo stage, indicating that Dicer1 exerted functions as a maternal effector. When conditionally knocking out of Dicer1 in growing oocytes, the Dicer1 null oocytes were mainly arrested at metaphase of the first meiosis (MI) stage (Murchison et al., 2007). Knocking out of Dicer1 induced the high expression of mouse transposon (MT) and SINE elements B1 and B2 (Murchison et al., 2007), which may be induced by abnormal DNA methylation pattern in Dicer1 null oocytes (Jeong and Lee, 2005). There is still no information about the effect of Dicer1 on early embryo DNA methylation dynamics, however, knocking down of Dicer1 could reduce the protein level of pluripotency factor Oct4 (Cui et al., 2007), indicating the pivotal roles of Dicer1 in preimplantation embryo development.

Other active DNA demethylation-associated factors include Elp3 (Okada et al., 2010), Gcm1 and Gcm2 (Hitoshi et al., 2011) and the mechanism details still need to be further analyzed.

\section{ACTIVE DNA DEMETHYLATION IS ESSENTIAL FOR EMBRYO DEVELOPMENT}

From the experiments of knockdown or knockout of genes like Tet3, it had been shown that the PPN DNA active demethylation was essential for mouse embryo development. As is well known, parthenogenetically activated oocyte-derived embryos mostly develop poorly after implantation and could not develop to term (Surani et al., 1984).
However, Kono et al. had produced a full-term parthenogenetic mouse by activation of the MII oocyte which was composed of enucleated MII oocyte cytoplasm and the nucleus from another donor MII oocyte. The donor oocyte was produced by transferring the H19-depleted diplotene oocyte (from one day old mouse) nucleus into a fully grown oocyte, and if the nucleus was from the wild type, parthenogenetic embryos could only live for 14 days (Kono et al., 2004; Kono et al., 1996). In addition, the parthenogenetically derived ESCs could be used to produce live parthenote pups by tetraploid embryo complementation (Chen et al., 2009). These results may indicate that: firstly, paternal DNA demethylation was not essential for embryo development and the active DNA demethylation was critical for the development of mammalian placenta; and secondly, if the genomic imprinting was adaptive, embryos could develop to term without PPN active DNA methylation.

The 5-mC oxidation-mediated active DNA demethylation also occurred in somatic cell nuclear transfer (SCNT) mouse 1-cell embryos (Wossidlo et al., 2011). However, the quality of SCNT-produced embryos was obviously lower than that of in vitro fertilization (IVF) or intracytoplasmic sperm injection (ICSI)-induced zygotes, which indicated that genomic reprogramming of the somatic cell nucleus by the MII oocyte might not be complete (Thuan et al., 2010; Yang et al., 2007). Recent evidence showed that the nucleus of ESCs, fetal fibroblast or cumulus cells could be reprogrammed by the cytoplasm of interphase 2-cell embryo blastomeres after cell cycle synchronization, however, the interphase 2-cell embryo cytoplasm only could support the cell cycle synchronized ESC nuclear transfer embryo development to term (Kang et al., 2014). These results showed that the epigenetic code established during the preimplantation stage is essential for embryo development to term, in which active DNA demethylation is critically essential.

\section{SPECIES-SPECIFIC ZYGOTIC DNA DEMETHYLATION}

Immunofluorescence data showed that the DNA methylation dynamic patterns of different species are not conserved. For human, monkey, rat and mouse, the $5-\mathrm{mC}$ signals were mostly lost in the PPNs whereas for the sheep, there was no obvious 5-mC signal lost in the PPN. The PPN 5-mC dynamic data of pig, cow, goat and rabbit is still not validated (Ma et al., 2012). Compared with the PPN 5-mC, the data of 5 -hmC was not enough to analyze the conservation among mammalian species. Evidence showed that the 5-hmC signals mainly increased in PPNs of cow and rabbit (Wossidlo et al., 2011), whereas the 5-hmC signals existed in both the PPN and MPN of pig zygotes (Lee et al., 2014). TET3induced DNA demethylation was critical for the maternalzygote transition (MZT) and the expression level of NANOG in blastocysts of pig, which suggested that the 5-mCs hydroxydation was important for early porcine embryo 


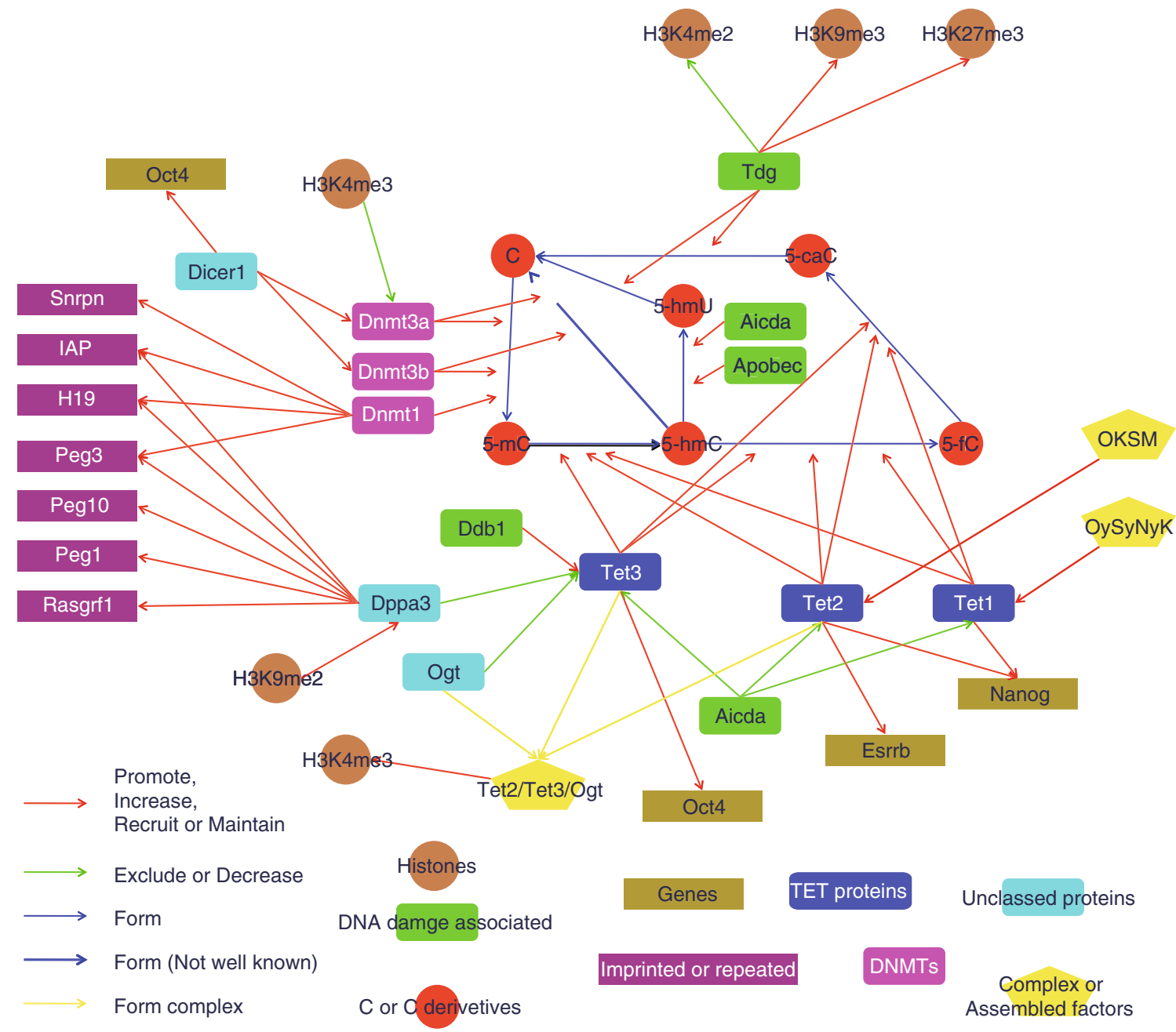

Figure 3. Molecular network regulating DNA demethylation in preimplantation embryos. The 5-mCs are mainly oxidated by TET proteins into 5-hmCs, 5-fCs or 5-caCs. The 5-hmCs could be targeted by Aicda, Apobec, Dnmt3a and Dnmt3b. The 5-caCs could be repaired into Cs (cytosines) by Tdg mediated base excision repair pathway. Most proteins participating directly in the DNA demethylation process could be taken as targets by other factors to regulate the DNA methylation pattern of specific genome regions, such as the localization of TET proteins could be affected by Aicda, Ogt and Dapp3, and the expression of Tet genes could be regulated by OSKM factors. In the preimplantation embryos, the DNA methylation imprinted genes and transposable elements IAP were mainly maintained by Dnmt1 and the Dapp3, however, the target sites of Dnmt1 and Dapp3 are different (see manuscript). In addition, the histone modifications and miRNAs can also affect or be affected by the active DNA demethylation process.

development (Lee et al., 2014). Although the information about active DNA demethylation among mammals is still not sufficient, due to the conservation of TET proteins in these species, we suspect that the zygotic active DNA demethylation may be ubiquitous in higher mammals.

\section{PERSPECTIVES}

The DNA demethylation in early embryos is complex and the DNA methylation patterns of CGIs, non CGI CpG sites, transposable elements, macro and minor satellites, and imprinted sequences are regulated by different proteins
(Fig. 3). Although more and more details about active DNA demethylation have been discovered, many questions remain to be answered, including: Which distinct functions of the three TET proteins are critical for preimplantation embryo development? By which mechanisms is Dnmt1 specifially targeted to the imprinted regions and some repeat sequences and by which mechanisms are TET proteins targeted to specific 5-mCs? Whether or not the order of the gene promoter active DNA demethylation is important for embryo development? Are the DNA methylation pattern differences in different blastomeres affecting their developmental fates? What are the key DNA regions for SCNT embryos in 
reprogramming? How to change DNA methylation pattern of specific region artificially? And so on.

\section{ACKNOWLEDGEMENTS}

We apologize to authors whose work could not be cited due to the scope of this review. Q.Y.S. was supported by the National Basic Research Program (973 Program) (Nos. 2012CB944404 and 2011CB944501). We would like to thank the members of the Shen laboratory for their kind and fruitful discussion of the manuscript.

\section{ABBREVIATIONS}

$\mathrm{BER}$, base excision repair; CGI, CpG island; DSB, double-strand break; ICM, inner cell mass; ICR, imprinting control regions; MPN, maternal pronucleus; MZT, maternal-zygote transition; PPN, paternal pronucleus; SCNT, somatic cell nuclear transfer; SSB, single-strand break.

\section{COMPLIANCE WITH ETHICS GUIDELINES}

The authors declare that there is no conflict of interest. This article does not contain any studies with human or animal subjects performed by the any of the authors.

\section{OPEN ACCESS}

This article is distributed under the terms of the Creative Commons Attribution License which permits any use, distribution, and reproduction in any medium, provided the original author(s) and the source are credited.

\section{REFERENCES}

Arioka Y, Watanabe A, Saito K, Yamada Y (2012) Activation-induced cytidine deaminase alters the subcellular localization of Tet family proteins. Plos One 7:e45031

Benetti R, Gonzalo S, Jaco I, Munoz P, Gonzalez S, Schoeftner S, Murchison E, Andl T, Chen T, Klatt $P$ et al (2008) A mammalian microRNA cluster controls DNA methylation and telomere recombination via Rbl2-dependent regulation of DNA methyltransferases. Nat struct mol biol 15:998

Blaschke K, Ebata KT, Karimi MM, Zepeda-Martinez JA, Goyal P, Mahapatra S, Tam A, Laird DJ, Hirst M, Rao A et al (2013) Vitamin $C$ induces Tet-dependent DNA demethylation and a blastocyst-like state in ES cells. Nature 500:222-226

Borgel J, Guibert S, Li Y, Chiba H, Schubeler D, Sasaki H, Forne T, Weber M (2010) Targets and dynamics of promoter DNA methylation during early mouse development. Nature genetics 42:1093-1100

Bortvin A, Goodheart M, Liao M, Page DC (2004) Dppa3/Pgc7/stella is a maternal factor and is not required for germ cell specification in mice. BMC dev biol 4:2

Chen X, Zhang Y, Douglas L, Zhou P (2001) UV-damaged DNAbinding proteins are targets of CUL-4A-mediated ubiquitination and degradation. J biol chem 276:48175-48182

Chen Z, Liu Z, Huang J, Amano T, Li C, Cao S, Wu C, Liu B, Zhou L, Carter MG et al (2009) Birth of parthenote mice directly from parthenogenetic embryonic stem cells. Stem Cells 27:2136-2145
Chen CC, Wang KY, Shen CK (2012) The mammalian de novo DNA methyltransferases DNMT3A and DNMT3B are also DNA 5-hydroxymethylcytosine dehydroxymethylases. $\mathrm{J}$ biol chem 287:33116-33121

Cirio MC, Ratnam S, Ding F, Reinhart B, Navara C, Chaillet JR (2008) Preimplantation expression of the somatic form of Dnmt1 suggests a role in the inheritance of genomic imprints. BMC dev biol 8:9

Cortazar D, Kunz C, Selfridge J, Lettieri T, Saito Y, MacDougall E, Wirz A, Schuermann D, Jacobs AL, Siegrist F et al (2011) Embryonic lethal phenotype reveals a function of TDG in maintaining epigenetic stability. Nature 470:419-423

Costa Y, Ding J, Theunissen TW, Faiola F, Hore TA, Shliaha PV, Fidalgo M, Saunders A, Lawrence M, Dietmann S et al (2013) NANOG-dependent function of TET1 and TET2 in establishment of pluripotency. Nature 495:370-374

Cui XS, Shen XH, Kim NH (2007) Dicer1 expression in preimplantation mouse embryos: Involvement of Oct3/4 transcription at the blastocyst stage. Biochemical and biophysical research communications 352:231-236

Derijck A, van der Heijden G, Giele M, Philippens M, de Boer P (2008) DNA double-strand break repair in parental chromatin of mouse zygotes, the first cell cycle as an origin of de novo mutation. Hum mol genet 17:1922-1937

Doege CA, Inoue K, Yamashita T, Rhee DB, Travis S, Fujita R, Guarnieri P, Bhagat G, Vanti WB, Shih A et al (2012) Early-stage epigenetic modification during somatic cell reprogramming by Parp1 and Tet2. Nature 488:652-655

Ficz G, Branco MR, Seisenberger S, Santos F, Krueger F, Hore TA, Marques CJ, Andrews S, Reik W (2011) Dynamic regulation of 5-hydroxymethylcytosine in mouse ES cells and during differentiation. Nature 473:398-402

Gao Y, Chen J, Li K, Wu T, Huang B, Liu W, Kou X, Zhang Y, Huang $\mathrm{H}$, Jiang $\mathrm{Y}$ et al (2013) Replacement of Oct4 by Tet1 during iPSC induction reveals an important role of DNA methylation and hydroxymethylation in reprogramming. Cell stem cell 12:453-469

Gaudet F, Rideout WM 3rd, Meissner A, Dausman J, Leonhardt H, Jaenisch R (2004) Dnmt1 expression in pre- and postimplantation embryogenesis and the maintenance of IAP silencing. Mol cell biol 24:1640-1648

Gu TP, Guo F, Yang H, Wu HP, Xu GF, Liu W, Xie ZG, Shi L, He X, Jin SG et al (2011) The role of Tet3 DNA dioxygenase in epigenetic reprogramming by oocytes. Nature 477:606-610

Hajkova P, Jeffries SJ, Lee C, Miller N, Jackson SP, Surani MA (2010) Genome-wide reprogramming in the mouse germ line entails the base excision repair pathway. Science 329:78-82

He YF, Li BZ, Li Z, Liu P, Wang Y, Tang Q, Ding J, Jia Y, Chen Z, Li L et al (2011) Tet-mediated formation of 5-carboxylcytosine and its excision by TDG in mammalian DNA. Science 333:1303-1307

Hirasawa R, Chiba H, Kaneda M, Tajima S, Li E, Jaenisch R, Sasaki $H$ (2008) Maternal and zygotic Dnmt1 are necessary and sufficient for the maintenance of DNA methylation imprints during preimplantation development. Genes dev 22:1607-1616

Hitoshi S, Ishino Y, Kumar A, Jasmine S, Tanaka KF, Kondo T, Kato S, Hosoya T, Hotta Y, Ikenaka K (2011) Mammalian Gcm genes induce Hes 5 expression by active DNA demethylation and induce neural stem cells. Nat neurosci 14:957-964 
Howell CY, Bestor TH, Ding F, Latham KE, Mertineit C, Trasler JM, Chaillet JR (2001) Genomic imprinting disrupted by a maternal effect mutation in the Dnmt1 gene. Cell 104:829-838

Huang Y, Pastor WA, Shen Y, Tahiliani M, Liu DR, Rao A (2010) The behaviour of 5-hydroxymethylcytosine in bisulfite sequencing. Plos One 5:e8888

Huang Y, Chavez L, Chang X, Wang X, Pastor WA, Kang J, ZepedaMartinez JA, Pape UJ, Jacobsen SE, Peters B et al (2014) Distinct roles of the methylcytosine oxidases Tet1 and Tet2 in mouse embryonic stem cells. Proc Natl Acad Sci USA 111:1361-1366

Inoue A, Zhang Y (2011) Replication-dependent loss of 5-hydroxymethylcytosine in mouse preimplantation embryos. Science 334:194

Inoue A, Matoba S, Zhang Y (2012) Transcriptional activation of transposable elements in mouse zygotes is independent of Tet3mediated 5-methylcytosine oxidation. Cell res 22:1640-1649

Iqbal K, Jin SG, Pfeifer GP, Szabo PE (2011) Reprogramming of the paternal genome upon fertilization involves genome-wide oxidation of 5-methylcytosine. Proc Natl Acad Sci USA 108:3642-3647

Ito S, Shen L, Dai Q, Wu SC, Collins LB, Swenberg JA, He C, Zhang $Y$ (2011) Tet proteins can convert 5-methylcytosine to 5-formylcytosine and 5-carboxylcytosine. Science 333:1300-1303

Jeong KS, Lee S (2005) Estimating the total mouse DNA methylation according to the $\mathrm{B} 1$ repetitive elements. Biochem biophys res commun 335:1211-1216

Kang E, Wu G, Ma H, Li Y, Tippner-Hedges R, Tachibana M, Sparman M, Wolf DP, Scholer HR, Mitalipov S (2014) Nuclear reprogramming by interphase cytoplasm of two-cell mouse embryos. Nature 509:101-104

Kelsey G, Feil R (2013) New insights into establishment and maintenance of DNA methylation imprints in mammals. Philos Trans R Soc Lond Ser B, Biol sci 368:20110336

Kobayashi H, Sakurai T, Imai M, Takahashi N, Fukuda A, Yayoi O, Sato S, Nakabayashi K, Hata K, Sotomaru Y et al (2012) Contribution of intragenic DNA methylation in mouse gametic DNA methylomes to establish oocyte-specific heritable marks. PLoS genet 8:e1002440

Kono T, Obata Y, Yoshimzu T, Nakahara T, Carroll J (1996) Epigenetic modifications during oocyte growth correlates with extended parthenogenetic development in the mouse. Nat genet 13:91-94

Kono T, Obata Y, Wu Q, Niwa K, Ono Y, Yamamoto Y, Park ES, Seo JS, Ogawa H (2004) Birth of parthenogenetic mice that can develop to adulthood. Nature 428:860-864

Kriaucionis S, Heintz N (2009) The nuclear DNA base 5-hydroxymethylcytosine is present in Purkinje neurons and the brain. Science 324:929-930

Kurihara Y, Kawamura Y, Uchijima Y, Amamo T, Kobayashi H, Asano T, Kurihara H (2008) Maintenance of genomic methylation patterns during preimplantation development requires the somatic form of DNA methyltransferase 1. Dev biol 313:335-346

Lan L, Nakajima S, Kapetanaki MG, Hsieh CL, Fagerburg M, Thickman K, Rodriguez-Collazo P, Leuba SH, Levine AS, RapicOtrin V (2012) Monoubiquitinated histone H2A destabilizes photolesion-containing nucleosomes with concomitant release of UV-damaged DNA-binding protein E3 ligase. J biol chem 287:12036-12049
Lee K, Hamm J, Whitworth K, Spate L, Park KW, Murphy CN, Prather RS (2014) Dynamics of TET family expression in porcine preimplantation embryos is related to zygotic genome activation and required for the maintenance of NANOG. Dev biol 386:86-95

Liu YJ, Nakamura T, Nakano T (2012) Essential role of DPPA3 for chromatin condensation in mouse oocytogenesis. Biol reprod 86:40

Ma JY, Liang XW, Schatten H, Sun QY (2012) Active DNA demethylation in mammalian preimplantation embryos: new insights and new perspectives. Mol hum reprod 18:333-340

Ma JY, Li M, Luo YB, Song S, Tian D, Yang J, Zhang B, Hou Y, Schatten H, Liu Z et al (2013) Maternal factors required for oocyte developmental competence in mice: transcriptome analysis of non-surrounded nucleolus (NSN) and surrounded nucleolus (SN) oocytes. Cell Cycle 12:1928-1938

Mayer W, Niveleau A, Walter J, Fundele R, Haaf T (2000) Demethylation of the zygotic paternal genome. Nature 403:501-502

Murchison EP, Stein P, Xuan Z, Pan H, Zhang MQ, Schultz RM, Hannon GJ (2007) Critical roles for Dicer in the female germline. Genes dev 21:682-693

Nakamura T, Arai Y, Umehara H, Masuhara M, Kimura T, Taniguchi H, Sekimoto T, Ikawa M, Yoneda Y, Okabe M et al (2007) PGC7/ Stella protects against DNA demethylation in early embryogenesis. Nat cell biol 9:64-71

Nakamura T, Liu YJ, Nakashima H, Umehara H, Inoue K, Matoba S, Tachibana M, Ogura A, Shinkai Y, Nakano T (2012) PGC7 binds histone $\mathrm{H} 3 \mathrm{~K} 9 \mathrm{me} 2$ to protect against conversion of $5 \mathrm{mC}$ to $5 \mathrm{hmC}$ in early embryos. Nature 486:415-419

Okada Y, Yamagata K, Hong K, Wakayama T, Zhang Y (2010) A role for the elongator complex in zygotic paternal genome demethylation. Nature 463:554-558

Okano M, Bell DW, Haber DA, Li E (1999) DNA methyltransferases Dnmt3a and Dnmt3b are essential for de novo methylation and mammalian development. Cell 99:247-257

Oswald J, Engemann S, Lane N, Mayer W, Olek A, Fundele R, Dean W, Reik W, Walter J (2000) Active demethylation of the paternal genome in the mouse zygote. Curr biol 10:475-478

Pastor WA, Pape UJ, Huang Y, Henderson HR, Lister R, Ko M, McLoughlin EM, Brudno Y, Mahapatra S, Kapranov P et al (2011) Genome-wide mapping of 5-hydroxymethylcytosine in embryonic stem cells. Nature 473:394-397

Pufulete M, Al-Ghnaniem R, Khushal A, Appleby P, Harris N, Gout S, Emery PW, Sanders TA (2005) Effect of folic acid supplementation on genomic DNA methylation in patients with colorectal adenoma. Gut 54:648-653

Rougier N, Bourc'his D, Gomes DM, Niveleau A, Plachot M, Paldi A, Viegas-Pequignot $E$ (1998) Chromosome methylation patterns during mammalian preimplantation development. Genes dev 12:2108-2113

Ruzov A, Tsenkina Y, Serio A, Dudnakova T, Fletcher J, Bai Y, Chebotareva T, Pells S, Hannoun Z, Sullivan G et al (2011) Lineage-specific distribution of high levels of genomic 5-hydroxymethylcytosine in mammalian development. Cell res 21:13321342

Santos F, Hendrich B, Reik W, Dean W (2002) Dynamic reprogramming of DNA methylation in the early mouse embryo. Dev biol 241:172-182 
Singh S, Li SS (2012) Epigenetic effects of environmental chemicals bisphenol a and phthalates. Int j mol sci 13:10143-10153

Smallwood SA, Tomizawa S, Krueger F, Ruf N, Carli N, SegondsPichon A, Sato S, Hata K, Andrews SR, Kelsey G (2011) Dynamic CpG island methylation landscape in oocytes and preimplantation embryos. Nat genet 43:811-814

Smith ZD, Chan MM, Mikkelsen TS, Gu H, Gnirke A, Regev A, Meissner A (2012) A unique regulatory phase of DNA methylation in the early mammalian embryo. Nature 484:339-344

Song CX, Szulwach KE, Fu Y, Dai Q, Yi C, Li X, Li Y, Chen CH, Zhang W, Jian $X$ et al (2011) Selective chemical labeling reveals the genome-wide distribution of 5-hydroxymethylcytosine. Nat biotechnol 29:68-72

Song CX, Szulwach KE, Dai Q, Fu Y, Mao SQ, Lin L, Street C, Li Y, Poidevin M, Wu H et al (2013) Genome-wide profiling of 5-formylcytosine reveals its roles in epigenetic priming. Cell 153:678-691

Surani MA, Barton SC, Norris ML (1984) Development of reconstituted mouse eggs suggests imprinting of the genome during gametogenesis. Nature 308:548-550

Tahiliani M, Koh KP, Shen Y, Pastor WA, Bandukwala H, Brudno Y, Agarwal S, Iyer LM, Liu DR, Aravind L et al (2009) Conversion of 5-methylcytosine to 5-hydroxymethylcytosine in mammalian DNA by MLL partner TET1. Science 324:930-935

Tan L, Shi YG (2012) Tet family proteins and 5-hydroxymethylcytosine in development and disease. Development 139:1895-1902

Thuan NV, Kishigami S, Wakayama T (2010) How to improve the success rate of mouse cloning technology. J reprod Dev 56:20-30

van Meel FC, Pearson PL (1979) Replacement of protamine by F1 histone during reactivation of fused human sperm nuclei. Histochemistry 63:329-339

Wang T, Wu H, Li Y, Szulwach KE, Lin L, Li X, Chen IP, Goldlust IS, Chamberlain SJ, Dodd A et al (2013) Subtelomeric hotspots of aberrant 5-hydroxymethylcytosine-mediated epigenetic modifications during reprogramming to pluripotency. Nat cell biol 15:700-711

Wang L, Zhang J, Duan J, Gao X, Zhu W, Lu X, Yang L, Li G, Ci W, Li W et al (2014) Programming and inheritance of parental DNA methylomes in mammals. Cell 157:979-991
Williams K, Christensen J, Pedersen MT, Johansen JV, Cloos PA, Rappsilber J, Helin K (2011) TET1 and hydroxymethylcytosine in transcription and DNA methylation fidelity. Nature 473:343-348

Wossidlo M, Arand J, Sebastiano V, Lepikhov K, Boiani M, Reinhardt $\mathrm{R}$, Scholer H, Walter J (2010) Dynamic link of DNA demethylation, DNA strand breaks and repair in mouse zygotes. EMBO j 29:1877-1888

Wossidlo M, Nakamura T, Lepikhov K, Marques CJ, Zakhartchenko V, Boiani M, Arand J, Nakano T, Reik W, Walter J (2011) 5 -Hydroxymethylcytosine in the mammalian zygote is linked with epigenetic reprogramming. Nat commun 2:241

Wu H, D'Alessio AC, Ito S, Wang Z, Cui K, Zhao K, Sun YE, Zhang Y (2011) Genome-wide analysis of 5-hydroxymethylcytosine distribution reveals its dual function in transcriptional regulation in mouse embryonic stem cells. Genes dev 25:679-684

Yang X, Smith SL, Tian XC, Lewin HA, Renard JP, Wakayama T (2007) Nuclear reprogramming of cloned embryos and its implications for therapeutic cloning. Nat genet 39:295-302

Yu C, Zhang YL, Pan WW, Li XM, Wang ZW, Ge ZJ, Zhou JJ, Cang Y, Tong C, Sun QY et al (2013) CRL4 complex regulates mammalian oocyte survival and reprogramming by activation of TET proteins. Science 342:1518-1521

Zhang Q, Liu X, Gao W, Li P, Hou J, Li J, Wong J (2014) Differential regulation of the ten-eleven translocation (TET) family of dioxygenases by $\mathrm{O}$-linked beta- $\mathrm{N}$-acetylglucosamine transferase (OGT). J biol chem 289:5986-5996

Zhao H, Chen T (2013) Tet family of 5-methylcytosine dioxygenases in mammalian development. J Hum genet 58:421-427

Zhu G, Li Y, Zhu F, Wang T, Jin W, Mu W, Lin W, Tan W, Li W, Street $R C$ et al (2014) Coordination of Engineered Factors with TET1/2 Promotes Early-Stage Epigenetic Modification during Somatic Cell Reprogramming. Stem cell reports 2:253-261

Ziegler-Birling C, Helmrich A, Tora L, Torres-Padilla ME (2009) Distribution of p53 binding protein 1 (53BP1) and phosphorylated H2A.X during mouse preimplantation development in the absence of DNA damage. Int j dev biol 53:1003-1011 